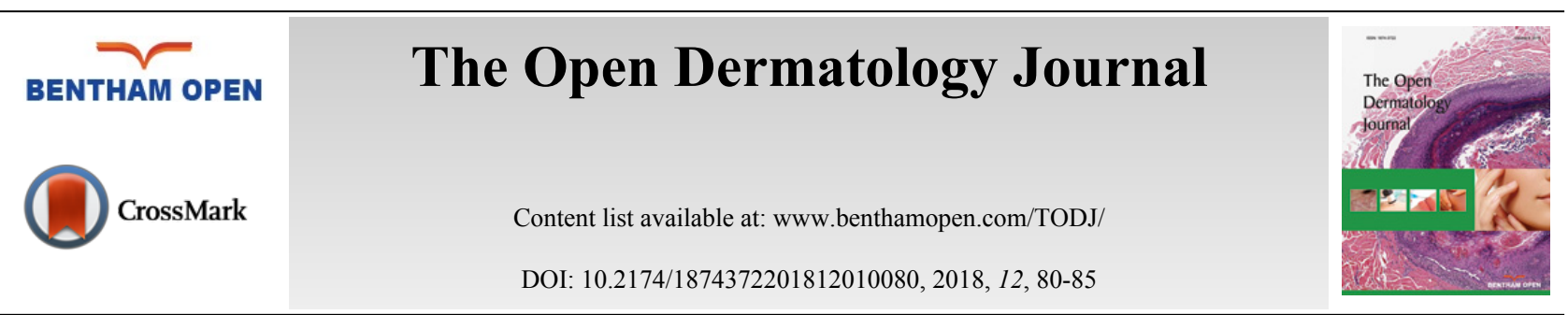

REVIEW ARTICLE

\title{
Virulent Acne Biofilms Offer Insight into Novel Therapeutic Options
}

\author{
Asha Gowda ${ }^{1, *}$ and Craig G. Burkhart ${ }^{2,3}$ \\ ${ }^{1}$ Medical Student, University of Toledo College of Medicine, Toledo, Ohio 43560, USA \\ ${ }^{2}$ Clinical Professor, University of Toledo College of Medicine, Toledo, Ohio 43560, USA \\ ${ }^{3}$ Clinical Assistant Professor, Ohio University College of Osteopathic Medicine, Athens, Ohio 43560, USA
}

Received: June 1, 2018

Revised: August 27, 2018

Accepted: September 15, 2018

\begin{abstract}
Acne vulgaris is a disease of the pilosebaceous unit that may manifest as either noninflammatory or inflammatory skin lesions. The microcomedone theory suggests that the first step in the pathogenesis of acne vulgaris is the noninflammatory comedone. The comedone is a collection of keratin and sebum that is trapped within the pilosebaceous unit due to hyperproliferation of keratinocytes in the follicular lining. The biofilm produced by P. acnes bacteria promotes the formation of a comedone by acting as a biological glue that prevents expulsion of the hyperkeratotic plug. In addition to its adhesive properties, the biofilm has virulence factors contributing to the pathogenicity of $P$. acnes in acne vulgaris. With further investigation and a better understanding of the $P$. acnes biofilm, new therapeutic options for acne vulgaris can be made available. By targeting the $P$. acnes biofilm, treatment can be made more effective and precise, without the concern of side effects seen in currently available acne medications.
\end{abstract}

Keywords: Acne, Comedonal acne, Comedone, P. acnes biofilm, Biological glue, Virulence factors.

\section{INTRODUCTION}

Acne vulgaris is a disease of the pilosebaceous unit. The etiology of acne has been studied extensively, and the pathogenesis is considered to be multifactorial, involving increased sebum production secondary to androgens, follicular hyperkeratinization, and colonization of the skin with Propionibacterium acnes [1]. Acne vulgaris may manifest as either noninflammatory or inflammatory skin lesions; however, inflammation is believed to occur secondary to an inciting event [2,3]. The microcomedone theory suggests that the initial phase of acne formation is comedogenesis, which involves androgens, hyperproliferation of keratinocytes in the follicular lining, and buildup of keratin and sebum within the pilosebaceous unit $[1,4]$.

Androgens, mainly testosterone and 5-a-dihydrotestosterone, bind to nuclear receptors in responsive sebocytes and trigger a cascade of events leading to sebum production within the pilosebaceous unit [5]. Excess sebum can accumulate due to increased levels of androgens and/or due to sebaceous glands with increased sensitivity to the effects of androgens [5]. Simultaneously, hyperproliferation of follicular keratinocytes entraps the sebum within. Given that keratinocytes, like sebocytes, have the machinery to metabolize androgens, hormonal imbalances may contribute to ductal hyperkeratinization as well [6]. Alternatively, follicular keratinocytes may accumulate secondary to abnormal desquamation due to increased proliferation of the deep basal keratinocytes or unregulated differentiation of the keratinocytes [7 - 9]. Other theories explaining the evolution of comedones suggest that keratinocyte proliferation is a response to variations in sebum composition, such as lower levels of linoleic acid [10], or that hyperkeratinization may be a response to the secretion of proinflammatory cytokines such as IL-1 that is induced by the presence of $P$. acnes on the skin [11]. Ultimately, the interaction of these factors and synchronized processes lead to the plugging of sebum and debris within the pilosebaceous unit. Clinically, this presents as a non-inflamed lesion or comedone.

\footnotetext{
* Address correspondence to this author at the Medical Student, University of Toledo College of Medicine, Toledo, 5600 Monroe Street, Suite 106B, Sylvania, OH 43560, USA; Fax: 2489321909; E-mail: asha.gowda@rockets.utoledo.edu
} 
This report discusses the $P$. acnes biofilm and its role in comedogenesis. We address the virulent properties of the biofilm that contribute to the pathogenesis of acne vulgaris and encourages that this biologically active component be further investigated as a therapeutic target. By targeting the $P$. acnes biofilm, acne vulgaris can be treated in its early phases. Furthermore, the treatment of acne vulgaris can be made more effective and precise, without the concern of side effects seen in currently available acne medications.

\section{DISCUSSION}

The biofilm concept in acne vulgaris offers an alternative explanation to the pathogenesis of the microcomedone $[12,13]$. A biofilm is a collection of microorganisms, or microcolonies, encased within a wall of polysaccharides and proteins that are secreted by the organism once it has adhered to a surface [12]. Bacteria within a biofilm are defined as sessile. Compared to the planktonic form, sessile bacteria are in a distinct metabolic state [14] and can change phenotypes related to behavior, gene expression, and protein synthesis $[15,16]$. The ability of $P$. acnes to produce biofilms on implant biomaterials was first shown in 2003 [17]. This phenomenon was supported by genome mapping of $P$. acnes, which revealed genetic machinery enabling the organism to synthesize a polysaccharide capsule [18]. It has since been demonstrated that $P$. acnes can adhere to and form an extracellular polymer on various biomaterials in vitro $[14,19,20]$, as well as in vivo [20] Similarly, immunofluorescence microscopy has revealed that acne-affected skin has an increased frequency of biofilm production [21].

The presence of biofilm within the pilosebaceous unit has been suggested to act as a biological glue that increases the cohesiveness between keratinocytes and provides a medium for $P$. acnes organisms to remain adhered to the follicular epithelium [13]. Thus, after hyperproliferation of keratinocytes from the follicular lining, the biofilm ultimately may be responsible for the formation of the comedone. The strong cohesive forces of the glue-like secretions prevent the hyperkeratotic plug from being expelled through the epidermal surface [1, 13]. Instead, as the comedone expands with debris, its immunogenic contents can be released into the surrounding dermal tissue [13]. This activates Toll-like receptors on keratinocytes and sebocytes and induces the production of proinflammatory cytokines [22, 23], leading to the development of inflamed pustules and papules.

The $P$. acnes biofilm is important not only because it promotes comedogenesis, but also because it increases the pathogenicity of the organism. $P$. acnes is a commensal organism of healthy skin and is considered a resident of the pilosebaceous unit [24]. Though the presence of $P$. acnes is involved in the etiology of acne vulgaris, there is no direct correlation between the number of bacteria and severity of acne [12]. Synthesis of biofilm by $P$. acnes may enable the commensal organism to transition into a pathogen. The ability to form biofilm can differ based on the isolate and $P$. acnes phylotype, designated as types IA, IB, II, and III [21, 25].

In one study, $P$. acnes biofilms in acne-affected sebaceous follicles were composed of $P$. acnes phenotypes IA and II and shown to express Christie-Atkins-Munch-Peterson (CAMP) 1 factor [21]. CAMP factor is toxic to keratinocytes and macrophages and can produce an inflammatory reaction in vivo through the binding of Toll-like receptors [26, 27]. Dermatan Sulfate-Binding Protein (DSBP), which recognizes the host proteins human fibrinogen and dermatan sulfate, is also expressed in $P$. acnes biofilms of specific phylotypes on the acne-infected skin [21]. This immunoreactive protein mediates the attachment of $P$. acnes bacteria to host cells and improves the survival capacity of $P$. acnes [28, 29]. Like DSBP, other adhesion proteins may exist within the $P$. acnes biofilm that promote irreversible attachment of the bacteria and cause acne to progress into a chronic disease. Bacterial lipases also are upregulated in $P$. acnes biofilm in vitro [19]. Increased levels of free fatty acids, secondary to the hydrolysis of triglycerides, have been shown to enhance the adherence of $P$. acnes bacteria and their ability to colonize the pilosebaceous unit [30]. In vivo, free fatty acids are comedogenic and can activate the inflammatory response [31,32].

Within a biofilm, organisms are equipped with protective strategies that are certainly impressive. Macrocolonies can live in an intimate milieu within a glycocalyx polymer wall that allows organisms to withstand stress. In addition to the physical barrier of the biofilm, bacteria can slow their rate of growth and upregulate proteins like multi-drug resistance pumps to block the effects of antimicrobial agents [16]. Activation of "Quorum sensing," [16] a form of intercellular communication utilizing molecules called autoinducers, enables the coordination of gene expression and promotes adaptation to environmental change [33, 34]. Mature $P$. acnes biofilms in vitro have been shown to have levels of autoinducer-2 that are three times higher than those in planktonic bacteria [19]. Though the composition of $P$. acnes biofilms has yet to be fully elucidated, it is reasonable to believe that at least twenty proteins, possibly with virulent properties and protective functions, are secreted extracellularly by $P$. acnes [35]. These findings explain how $P$. acnes can become pathogenic and why sessile $P$. acnes organisms are more resistant to antimicrobials than their planktonic 
counterparts $[19,36]$.

Available therapies for acne can be very effective, however, failed treatments are common and these medications are not entirely harmless. For instance, topical antimicrobials have an associated risk of generating highly resistant strains of bacteria, and so they are not recommended as monotherapy and should be combined with bactericidal agents like benzoyl peroxide. Furthermore, antibiotics lack specificity and can disrupt the microflora of the body by affecting other commensal organisms [37]. Topical retinoids such as adapalene, tretinoin, isotretinoin, and tazarotene are unplugging agents that normalize the hyperproliferation of keratinocytes, increase cell turnover, and enhance the desquamation of follicular keratinocytes. Though these topicals can be potent, reactions such as irritant dermatitis can often become a limitation to its use. Safety also becomes an issue with oral medications such as hormonal therapy and isotretinoin, which are contraindicated in certain populations and have systemic side effects requiring close follow up with extensive workup.

By targeting proteins and molecules within the $P$. acnes biofilm, treatment can be made precise with fewer adverse effects. Currently, few treatment modalities have been suggested to successfully target the P. acnes biofilm. CAMP factor, a component of the $P$. acnes biofilm, recently was identified as a therapeutic target. Passive immunization with vaccines neutralized CAMP factor and suppressed the inflammatory response in mice, without affecting the colonization of other harmless organisms [37].

Several agents that are frequently used in acne vulgaris have been shown to prevent the formation of and shrink the P. acnes biofilm in vitro. Antimicrobials such as $0.5 \%$ erythromycin, $2 \%$ salicylic acid, $0.1 \%$ triclosan, $0.5 \%$ minocycline, and combinations of such agents, including $5 \%$ benzoyl peroxide and $0.5 \%$ erythromycin, and $5 \%$ benzoyl peroxide and $1 \%$ clindamycin, were observed to cause a significant reduction in biofilm mass [19]. Similarly, the antimicrobial Decanediol led to reductions in mature biofilm mass, and furthermore, also inhibited the formation of biofilm by bacteria in a dose-dependent manner [38].

Additionally, few natural and chemical compounds have been isolated and discovered to have activity against the $P$. acnes biofilm. The combination of ellagic acid $\left(250 \mu \mathrm{g} \mathrm{ml}^{-1}\right)$, a polyphenol found in many plants, and tetracycline $\left(0.312 \mu \mathrm{g} \mathrm{ml}^{-1}\right)$ inhibited biofilm secretion in vitro and in vivo in C. elegans [39]. Myrtle extract from the plant $M$. communis revealed anti-biofilm properties when used at concentrations between $0.1 \%$ and $0.001 \%$ in vitro [40]. Likewise, icariin, resveratrol, and salidroside, which are active compounds in several plant extracts, also have demonstrated antibiofilm effects against the $P$. acnes biofilm [41]. One study showed that two thiazolidinedione derivatives, (Z)-5-octylidenethiazolidine-2,4-dione $\left(100 \mu \mathrm{mol} 1^{-1}\right)$ and (Z)-5-decylidenethiazolidine-2,4-dione (100 $\mu \mathrm{mol}$ $1^{-1}$ ), known to be quorum sensing inhibitors, led to significant reductions in $P$. acnes biofilm mass, likely by mechanisms that affect biofilm development after its initial adherence to surfaces [42]. Another clinical study with 64 patients, tested a topical agent comprised of a chelating agent, buffer, isopropyl alcohol, and surfactant, specifically designed to target the P. acnes biofilm. By mechanisms believed to destroy bonds within the extracellular polysaccharides enveloping biofilms, this agent effectively reduced acne lesions and symptoms in patients [43].

\section{CONCLUSION}

We believe that the inciting event for acne vulgaris involves the $P$. acnes biofilm, which is a key player in the virulence of the organism. Inhibition of biofilm synthesis can prevent acne vulgaris at an early stage, prior to the development of comedones and their progression into inflammatory papules and pustules. With a better understanding of the $P$. acnes biofilm structure, composition, and functions, new treatment strategies for acne vulgaris can be established.

\section{CONSENT FOR PUBLICATION}

Not applicable.

\section{CONFLICT OF INTEREST}

The authors declare no conflict of interest, financial or otherwise.

\section{ACKNOWLEDGEMENTS}

Declared none. 


\section{REFERENCES}

[1] Zaenglein AL, Thiboutot CM. Acne vulgaris. China: Elsevier 2018; pp. 588-603.

[2] Dessinioti C, Katsambas AD. The role of Propionibacterium acnes in acne pathogenesis: Facts and controversies. Clin Dermatol 2010; 28(1): 2-7. [http://dx.doi.org/10.1016/j.clindermatol.2009.03.012] [PMID: 20082942]

[3] Orentreich N, Durr NP. The natural evolution of comedones into inflammatory papules and pustules. J Invest Dermatol 1974; 62: 316-20. [http://dx.doi.org/10.1111/1523-1747.ep12724274]

[4] Holmes RL, Williams M, Cunliffe WJ. Pilo-sebaceous duct obstruction and acne. Br J Dermatol 1972; 87(4): $327-32$. [http://dx.doi.org/10.1111/j.1365-2133.1972.tb07418.x] [PMID: 4263289]

[5] Gollnick H, Cunliffe W, Berson D, et al. Management of acne: A report from a global alliance to improve outcomes in acne. J Am Acad Dermatol 2003; 49(1)(Suppl.): S1-S37. [http://dx.doi.org/10.1067/mjd.2003.618] [PMID: 12833004]

[6] Milewich L, Kaimal V, Shaw CB, Sontheimer . Epidermal keratinocytes: A source of 5 alpha-dihydrotestosterone production in human skin. J Clin Endocrinol Metab 1986; 62(4): 739-46. [http://dx.doi.org/10.1210/jcem-62-4-739] [PMID: 3949953]

[7] Plewig G, Fulton JE, Kligman AM. Cellular dynamics of comedo formation in acne vulgaris. Arch Dermatol Forsch 1971; 242 (1): 12-29. [http://dx.doi.org/10.1007/BF00595286] [PMID: 4258128]

[8] Knaggs HE, Holland DB, Morris C, Wood EJ, Cunliffe WJ. Quantification of cellular proliferation in acne using the monoclonal antibody Ki-67. J Invest Dermatol 1994; 102(1): 89-92. [http://dx.doi.org/10.1111/1523-1747.ep12371738] [PMID: 8288915]

[9] Hughes BR, Morris C, Cunliffe WJ, Leigh IM. Keratin expression in pilosebaceous epithelia in truncal skin of acne patients. Br J Dermatol 1996; 134(2): 247-56. [http://dx.doi.org/10.1111/j.1365-2133.1996.tb07609.x] [PMID: 8746337]

[10] Downing DT, Stewart ME, Wertz PW, Strauss JS. Essential fatty acids and acne. J Am Acad Dermatol 1986; 14(2 Pt 1): $221-5$. [http://dx.doi.org/10.1016/S0190-9622(86)70025-X] [PMID: 2936775]

[11] Selway JL, Kurczab T, Kealey T, Langlands K. Toll-like receptor 2 activation and comedogenesis: Implications for the pathogenesis of acne. BMC Dermatol 2013; 13: 10. [http://dx.doi.org/10.1186/1471-5945-13-10] [PMID: 24011352]

[12] Burkhart CN, Burkhart CG. Microbiology's principle of biofilms as a major factor in the pathogenesis of acne vulgaris. Int J Dermatol 2003; 42(12): 925-7. [http://dx.doi.org/10.1111/j.1365-4632.2003.01588.x] [PMID: 14636182]

[13] Burkhart CG, Burkhart CN. Expanding the microcomedone theory and acne therapeutics: Propionibacterium acnes biofilm produces biological glue that holds corneocytes together to form plug. J Am Acad Dermatol 2007; 57(4): 722-4. [http://dx.doi.org/10.1016/j.jaad.2007.05.013] [PMID: 17870436]

[14] Holmberg A, Lood R, Mörgelin M, et al. Biofilm formation by Propionibacterium acnes is a characteristic of invasive isolates. Clin Microbiol Infect 2009; 15(8): 787-95. [http://dx.doi.org/10.1111/j.1469-0691.2009.02747.x] [PMID: 19392888]

[15] Archer NK, Mazaitis MJ, Costerton JW, Leid JG, Powers ME, Shirtliff ME. Staphylococcus aureus biofilms: Properties, regulation, and roles in human disease. Virulence $2011 ; 2(5): 445-59$. [http://dx.doi.org/10.4161/viru.2.5.17724] [PMID: 21921685]

[16] Sulzberger M, Fölster H, Sattler M, Rippke F, Grönniger E. Inhibition of Propionibacterium acnes associated biofilm formation by Decanediol. J Dermatol Sci 2016; 83(2): 159-61. [http://dx.doi.org/10.1016/j.jdermsci.2016.05.003] [PMID: 27188522]

[17] Ramage G, Tunney MM, Patrick S, Gorman SP, Nixon JR. Formation of Propionibacterium acnes biofilms on orthopaedic biomaterials and their susceptibility to antimicrobials. Biomaterials 2003; 24(19): 3221-7. [http://dx.doi.org/10.1016/S0142-9612(03)00173-X] [PMID: 12763449]

[18] Brüggemann H. Insights in the pathogenic potential of Propionibacterium acnes from its complete genome. Semin Cutan Med Surg 2005; 24(2): 67-72.

[http://dx.doi.org/10.1016/j.sder.2005.03.001] [PMID: 16092793]

[19] Coenye T, Peeters E, Nelis HJ. Biofilm formation by Propionibacterium acnes is associated with increased resistance to antimicrobial agents and increased production of putative virulence factors. Res Microbiol 2007; 158(4): 386-92. [http://dx.doi.org/10.1016/j.resmic.2007.02.001] [PMID: 17399956]

[20] Bayston R, Ashraf W, Barker-Davies R, et al. Biofilm formation by Propionibacterium acnes on biomaterials in vitro and in vivo: Impact on diagnosis and treatment. J Biomed Mater Res A 2007; 81(3): 705-9. [http://dx.doi.org/10.1002/jbm.a.31145] [PMID: 17187384]

[21] Jahns AC, Lundskog B, Ganceviciene R, et al. An increased incidence of Propionibacterium acnes biofilms in acne vulgaris: A case-control 
study. Br J Dermatol 2012; 167(1): 50-8.

[http://dx.doi.org/10.1111/j.1365-2133.2012.10897.x] [PMID: 22356121]

[22] Kim J, Ochoa MT, Krutzik SR, et al. Activation of toll-like receptor 2 in acne triggers inflammatory cytokine responses. J Immunol 2002; 169(3): 1535-41. [http://dx.doi.org/10.4049/jimmunol.169.3.1535] [PMID: 12133981]

[23] Nagy I, Pivarcsi A, Koreck A, Széll M, Urbán E, Kemény L. Distinct strains of Propionibacterium acnes induce selective human $\beta$-defensin-2 and interleukin-8 expression in human keratinocytes through toll-like receptors. J Invest Dermatol 2005; 124(5): 931-8. [http://dx.doi.org/10.1111/j.0022-202X.2005.23705.x] [PMID: 15854033]

[24] Grice EA, Segre JA. The skin microbiome. Nat Rev Microbiol 2011; 9(4): 244-53. [http://dx.doi.org/10.1038/nrmicro2537] [PMID: 21407241]

[25] Okuda KI, Nagahori R, Yamada S, et al. The composition and structure of biofilms developed by Propionibacterium acnes isolated from cardiac pacemaker devices. Front Microbiol 2018; 9: 182. [http://dx.doi.org/10.3389/fmicb.2018.00182] [PMID: 29491850]

[26] Nakatsuji T, Tang DC, Zhang L, Gallo RL, Huang CM. Propionibacterium acnes CAMP factor and host acid sphingomyelinase contribute to bacterial virulence: Potential targets for inflammatory acne treatment. PLoS One 2011; 6(4): e14797. [http://dx.doi.org/10.1371/journal.pone.0014797] [PMID: 21533261]

[27] Lheure C, Grange PA, Ollagnier G, et al. TLR-2 recognizes Propionibacterium acnes CAMP factor 1 from highly inflammatory strains. PLoS One 2016; 11(11): e0167237. [http://dx.doi.org/10.1371/journal.pone.0167237] [PMID: 27902761]

[28] Grange PA, Raingeaud J, Morelle W, Marcelin AG, Calvez V, Dupin N. Characterization of a Propionibacterium acnes surface protein as a fibrinogen-binding protein. Sci Rep 2017; $7(1): 6428$. [http://dx.doi.org/10.1038/s41598-017-06940-3] [PMID: 28743910]

[29] Lodes MJ, Secrist H, Benson DR, et al. Variable expression of immunoreactive surface proteins of Propionibacterium acnes. Microbiology 2006; 152(Pt 12): 3667-81. [http://dx.doi.org/10.1099/mic.0.29219-0] [PMID: 17159220]

[30] Gribbon EM, Cunliffe WJ, Holland KT. Interaction of Propionibacterium acnes with skin lipids in vitro. J Gen Microbiol 1993; 139(8): $1745-51$. [http://dx.doi.org/10.1099/00221287-139-8-1745] [PMID: 8409917]

[31] Marples RR, Downing DT, Kligman AM. Control of free fatty acids in human surface lipids by Corynebacterium acnes. J Invest Dermatol 1971; 56(2): 127-31.

[http://dx.doi.org/10.1111/1523-1747.ep12260695] [PMID: 4997367]

[32] Kligman AM, Wheatley VR, Mills OH. Comedogenicity of human sebum. Arch Dermatol 1970; 102(3): 267-75. [http://dx.doi.org/10.1001/archderm.1970.04000090029005] [PMID: 4247928]

[33] Lwin SM, Kimber I, McFadden JP. Acne, quorum sensing and danger. Clin Exp Dermatol 2014; 39(2): $162-7$. [http://dx.doi.org/10.1111/ced.12252] [PMID: 24524558]

[34] Ng WL, Bassler BL. Bacterial quorum-sensing network architectures. Annu Rev Genet 2009; 43: $197-222$. [http://dx.doi.org/10.1146/annurev-genet-102108-134304] [PMID: 19686078]

[35] Holland C, Mak TN, Zimny-Arndt U, et al. Proteomic identification of secreted proteins of Propionibacterium acnes. BMC Microbiol 2010; 10: 230 .

[http://dx.doi.org/10.1186/1471-2180-10-230] [PMID: 20799957]

[36] Gilbert P, Das J, Foley I. Biofilm susceptibility to antimicrobials. Adv Dent Res 1997; 11(1): 160-7. [http://dx.doi.org/10.1177/08959374970110010701] [PMID: 9524452]

[37] Liu PF, Nakatsuji T, Zhu W, Gallo RL, Huang CM. Passive immunoprotection targeting a secreted CAMP factor of Propionibacterium acnes as a novel immunotherapeutic for acne vulgaris. Vaccine $2011 ; 29(17): 3230-8$. [http://dx.doi.org/10.1016/j.vaccine.2011.02.036] [PMID: 21354482]

[38] Sulzberger M, Fölster H, Sattler M, Rippke F, Grönniger E. Inhibition of Propionibacterium acnes associated biofilm formation by Decanediol. J Dermatol Sci 2016; 83(2): 159-61. [http://dx.doi.org/10.1016/j.jdermsci.2016.05.003] [PMID: 27188522]

[39] Sivasankar C, Maruthupandiyan S, Balamurugan K, James PB, Krishnan V, Pandian SK. A combination of ellagic acid and tetracycline inhibits biofilm formation and the associated virulence of Propionibacterium acnes in vitro and in vivo. Biofouling 2016; 32(4): 397-410. [http://dx.doi.org/10.1080/08927014.2016.1148141] [PMID: 26930280]

[40] Feuillolay C, Pecastaings S, Le Gac C, et al. A Myrtus communis extract enriched in myrtucummulones and ursolic acid reduces resistance of Propionibacterium acnes biofilms to antibiotics used in acne vulgaris. Phytomedicine 2016; 23(3): 307-15. [http://dx.doi.org/10.1016/j.phymed.2015.11.016] [PMID: 26969384]

[41] Coenye T, Brackman G, Rigole P, et al. Eradication of Propionibacterium acnes biofilms by plant extracts and putative identification of icariin, resveratrol and salidroside as active compounds. Phytomedicine 2012; 19(5): 409-12. [http://dx.doi.org/10.1016/j.phymed.2011.10.005] [PMID: 22305279] 
[42] Brackman G, Forier K, Al Quntar AA, et al. Thiazolidinedione derivatives as novel agents against Propionibacterium acnes biofilms. J Appl Microbiol 2014; 116(3): 492-501.

[http://dx.doi.org/10.1111/jam.12378] [PMID: 24251377]

[43] Bernhardt MJ, Myntti MF. Topical treatment with an agent disruptive to $P$. acnes biofilm provides positive therapeutic response: Results of a randomized clinical trial. J Drugs Dermatol 2016; 15(6): 677-83.

[PMID: 27272073]

\section{(C) 2018 Gowda and Burkhart.}

This is an open access article distributed under the terms of the Creative Commons Attribution 4.0 International Public License (CC-BY 4.0), a copy of which is available at: (https://creativecommons.org/licenses/by/4.0/legalcode). This license permits unrestricted use, distribution, and reproduction in any medium, provided the original author and source are credited. 